\title{
Identification of the Predictive Power of Five Factor Personality Traits for Individual Instrument Performance Anxiety
}

\author{
Gökhan Özdemir ${ }^{1}$, Esra Dalkıran ${ }^{1}$ \\ ${ }^{1}$ Faculty of Education, Mehmet Akif Ersoy University, Burdur, Turkey \\ Correspondence: Gökhan Özdemir Faculty of Education, Mehmet Akif Ersoy University, Burdur, Turkey.
}

Received: July 3, $2017 \quad$ Accepted: August 3, $2017 \quad$ Online Published: August 8, 2017

doi:10.11114/jets.v5i9.2522 URL: https://doi.org/10.11114/jets.v5i9.2522

\begin{abstract}
This study, with the aim of identifying the predictive power of the five-factor personality traits of music teacher candidates on individual instrument performance anxiety, was designed according to the relational screening model. The study population was students attending the Music Education branch of Fine Arts Education Departments in Educational Faculties in Turkey with the sample comprising 256 students attending the Music Education branch of Mehmet Akif Ersoy University, Pamukkale University and Muğla Sttkı Koçman University during the 2016-2017 academic year. For data collection in the study, the Individual Instrument Performance Test Anxiety Scale developed by Dalkıran et al. (2014) and the Adjective-based Personality Test developed by Bacanlı et al. (2009) according to the five factor concept were used. Correlation analysis was performed to test whether there was a significant correlation between the individual instrument performance anxiety of students and the five factor personality traits. Additionally, to determine the predictive power of the five factor personality traits on individual instrument test performance anxiety of Music Education branch students, standard multiple regression analysis was performed. Data were tested at the significance level of 0.05 . According to the obtained data, it can be said there is a significant correlation between the individual instrument performance anxiety levels and the five factor personality traits of Music Education branch students. A positive and high level relationship was identified between performance anxiety levels and the five factor personality trait of emotional balance/neuroticism, while there was no correlation with agreeableness and performance anxiety level. Extraversion and openness to experience had a negative correlation with performance anxiety level, while there was a positive correlation observed between conscientiousness and performance anxiety. The five factor personality traits of emotional balance/neuroticism and conscientiousness positively and significantly predicted performance anxiety, while extraversion negatively and significantly predicted performance anxiety level. Contrarily, openness to experience and agreeableness were not identified to significantly predict performance anxiety level.
\end{abstract}

Keywords: personality, five factor model, anxiety

\section{Introduction}

Personality comprises the emotional, thought and behavior patterns that are similar among individuals, which reflect who we are and holistically determine our emotional, behavioral and cognitive style (Mount et al., 2005: 448). When our surroundings are examined, individuals appear to have emotional responses to events and situations. Some people are tolerant, while others have the opposite structure. People may be observed who are energetic, conscientious, compliant, mild-mannered in social relationships and with a wide social circle. The model describing individuals with these traits is the Five Factor Model (McCrea and Costa, 2003; cited in Eryılmaz, Öğülmüş, 2010). The basis of the five factor approach is that the perceived personality traits will reflect discourse in daily experiences in a variety of cultures and the view that individual differences will be coded in different words in the language (Somer, 1998). The five factor model is an important determinant of individual behavior in work and social environments. The basic tool used to measure personality, the collection of the individual's physiological, mental and emotional traits, are personality tests. Within the variety of personality tests claiming to measure different dimensions, one of the most commonly used is the Five Factor personality model with broad acceptance in academic and business worlds (Costa, et al., 1991; McCrae and Costa, 1987, cited in Sığrı, Gürbüz, 2010).

The five factor model, claiming to represent the basic dimensions of personality, is based on 4 rationales.

- based on longitudinal and experimental studies, 
- the characteristics of each factor are within the multiplicity of the personality system and description of qualities is based on natural language

- though different cultures may use different expressions, these factors are found in different age, gender, race and language groups

- and have some biological basis (Costa and McCrae, 1992).

These factors of extraversion, emotional balance/neuroticism, agreeableness, conscientiousness and openness to experience/culture have been confirmed by studies in many cultures (Bacanl, İlhan and Aslan, 2009). The defining characteristics of these factors are as follows:

Extraversion; comprises traits like being energetic, talkative, warm-blooded, excitable and enthusiastic and social. Individuals with high level of extraversion can be assessed as individuals who form relationships with others easily, like being with people, tend to cooperate, and are sympathetic. Those who have low extraversion levels, in other words introverts, may be evaluated as individuals who are withdrawn, do not like socializing, keep their distance from others, tend to remain silent, are shy and timid (Benet-Martinez and John, 1998; Somer, Korkmaz and Tatar, 2002; cited in Doğan, 2013).

Emotional balance/neuroticism; Also called neuroticism, it is defined by traits like worry, insecurity, concern with oneself, anger and anxiety, in a range of research. McCrae and Costa (1987) indicated there was growing consensus that the basis of neuroticism included negative emotions like anxiety, depression, anger and distress. Some other researchers explained that neuroticism was related to irrational thinking and insufficiency of coping mechanisms. People with high points for the neuroticism factor commonly have to deal with complicated emotions, and may use inappropriate coping mechanisms such as delusional thoughts and hostile reactions (Amirkhan, Risinger and Swickert, 1995; Matthews, Derryberry and Siegle, 2000; cited in Somer, Korkmaz and Tatar, 2002).

Agreeableness; a tendency for prosocial behavior. The most defining characteristics of agreeable individuals is their humanity, friendliness, warmth and tolerance. The basic characteristics representing the fifth factor of personality of conscientiousness are leadership, self-discipline, goal orientation, sufficiency, organization, awareness of duty, productivity and decisiveness (Chamorro-Premuzic, 2007; cited in Çivitci, Arıcıoğlu, 2012). Individuals with high levels of agreeableness are assessed as liking other people, and being giving and compassionate (Somer et al., 2002). Individuals with low agreeableness are vindictive, arrogant, stubborn, competitive, quarrelsome and difficult to reconcile (Bacanlı et al., 2009; Costa and McCrae, 1995; cited in Doğan, 2013).

Conscientiousness; comprises the traits of being disciplined, aware of duty, organized, attentive and careful. Individuals with high levels of conscientiousness are assessed as being oriented toward success, determined, plan and think before acting. Individuals with low conscientiousness levels are evaluated as being disorganized, undisciplined, tending to laziness and unaware of responsibilities (Bacanlı et al., 2009; Costa and McCrae, 1995; cited in Doğan, 2013).

Openness to experience/culture; the fifth factor is the factor with least consensus between researchers of the model. Some researchers name this intelligence; some others call it culture, while others name it openness to experience. Among the defining characteristics of the factor are adjectives like analytic, complicated, curious, independent, creative, liberal, non-traditional, original, strong imagination, broad interests, brave, love change, artistic and open-minded (Somer et al., 2002).

Research has shown that personality traits and anxiety levels are related (Bacanl1, 2009, Çırakoğlu, 2013, Kenny et al., 2004, Stephenson and Quarrier, 2005). A form of anxiety most commonly focused on during music education is performance anxiety. Performance anxiety is defined as an anxiety situation occurring related to fear of lack of control of a person's own movements or making a mistake in front of other people (Cox and Kenardy, 1993; cited in Dalkıran et al., 2014). An individual instrument exam where the student performs their individual instrument is the most common situation where performance anxiety may be experienced.

Zeidner (1988) described exam anxiety as multi-dimensional symptoms including phenomenologic, psychological and behavioral reactions as a whole occurring with the expectation of failure or negative results before an exam or similar evaluation situation.

During the instrument training process, anxiety experienced during exams may negatively affect academic success due to the student's performance. Considering that identification of the relationship between anxiety and personality traits may positively affect the student's performance and anxiety, the aim of this study was to investigate the correlation between the individual instrument performance anxiety and five factor personality traits of Music Education branch students. During this study the answers to the following two questions were sought:

1. Is there a significant correlation between students' individual instrument performance anxiety and five factor personality traits? 
2. To what extent do the personality traits of Music Education branch students predict individual instrument exam performance anxiety?

\section{Method}

\subsection{Design of the Study}

This study used a relational screening model to identify the power of five factor personality traits of music teacher candidates to predict individual instrument performance anxiety.

\subsection{Sample of the Study}

The population of the research comprised undergraduate students attending the Music Education branch of Fine Arts Education Departments in Education Faculties in Turkey. The sample comprised 256 undergraduate students attending the Music Education branch of Mehmet Akif Ersoy University, Pamukkale University and Muğla Sttkı Koçman University during the 2016-2017 academic year.

\subsection{Data Collection Instruments}

For data collection during the research, the Individual Instrument Performance Test Anxiety Scale developed by Dalkıran et al. (2014) and the Adjective-based Personality Test developed by Bacanlı et al. (2009) according to the five factor concept were used.

\subsubsection{Individual Instrument Performance Test Anxiety Scale}

The individual instrument performance exam anxiety scale was developed by Dalkıran, Baltacı, Karataş and Nacakcı in 2014. This study included a total of 750 students, 438 female and 312 male, attending Music Education branches in 10 universities and explanatory and confirmatory factor analysis results obtained a single dimension structure comprising 14 items. For the differentiation power of the items, $t$ values related to differences in item points in the $27 \%$ upper and lower groups and item total correlation coefficients were calculated and both analysis results observed the items were distinctive. The internal consistency Cronbach Alpha coefficient was calculated as .94, with test-repeat test reliability coefficient calculated as .93 for the scale. For this study, the Cronbach alpha coefficient of the scale was again calculated as .94 .

\subsubsection{Adjective-based Personality Test}

This test developed by Bacanl, İlhan and Aslan in 2009 has a seven point Likert-type scale, with questions to measure the five different personality traits. To test the validity of the Adjective-based Personality Test (ABPT), principal component analysis was completed and the direct oblique rotation method was used. Based on the factor analysis results, 40 pairs of adjectives were determined from 50 and factor analysis of the items found that the ABPT explained 52.6\% of the variance in the five dimensions. To test the reliability of the ABPT the test was repeated at a two week interval and the Cronbach alpha internal consistency coefficients for the scale dimensions were calculated. All coefficients were observed to be larger than 0.70 . In the study the Cronbach alpha coefficient of the scale was calculated as .82. For external validity studies, the Positive and Negative Affect Schedule developed by Watson et al. in 2004, the State-Trait Anxiety Inventory developed by Spielberger et al. and adapted to Turkish by Öner and Le Compte in 1998 and the Conflict Response Scale developed by Demirci (2004) were used. The results of applications for external validity observed that there was a significant correlation between personality dimensions and the scales used.

\subsection{Procedure}

Data was collected by the researchers with permission of the lecturers over nearly 15 minutes within class time. The students were informed of the aim of the research and students who volunteered to participate in the study completed the data collection tools.

\subsection{Analysis of Data}

The number of students participating in the study was 278; however considering the consistency of answers given to questions, the responses from 22 students were not included in the study. The research first included descriptive statistic information to investigate the individual instrument test performance anxiety levels of music education students according to the five factor personality traits (emotional balance/neuroticism, extraversion, openness to experience, agreeableness and conscientiousness). Later correlation analysis was performed to test whether there was a significant relationship between the individual instrument performance anxiety of students and five factor personality traits. Additionally, to determine the predictive power of the five factor personality traits for the individual instrument test performance anxiety of Music Education branch students, standard multiple regression analysis was used. Data were tested at the 0.05 significance level. 


\section{Results}

The descriptive statistical data for individual instrument test performance anxiety levels of Music Education branch students and five factor personality trait variables is shown in Table 1.

Table 1. Descriptive Statistics of variables

\begin{tabular}{llllll}
\hline & N & Min. & Max. & $x$ & s \\
\hline Performance Anxiety Level & 256 & 14.00 & 70.00 & 45.34 & 13.29 \\
Emotional Balance/Neuroticism & 256 & 11.00 & 49.00 & 33.02 & 8.12 \\
Extraversion & 256 & 9.00 & 63.00 & 29.34 & 13.98 \\
Openness to experience & 256 & 8.00 & 56.00 & 26.54 & 12.86 \\
Agreeableness & 256 & 9.00 & 63.00 & 40.59 & 15.13 \\
Conscientiousness & 256 & 7.00 & 49.00 & 33.43 & 10.09 \\
\hline
\end{tabular}

The correlation analysis results for the relationship between individual instrument test performance anxiety levels of Music Education branch students and five factor personality traits are shown in Table 2.

Table 2. Correlation coefficients between variables

\begin{tabular}{|c|c|c|c|c|c|c|}
\hline & 1 & 2 & 3 & 4 & 5 & 6 \\
\hline 1. Performance Anxiety Level & - & & & & & \\
\hline 2. Emotional balance/neuroticism & $.808^{* *}$ & - & & & & \\
\hline 3. Extraversion & $-.631^{* *}$ & $-.518^{* *}$ & - & & & \\
\hline 4. Openness to experience & $-.563^{* *}$ & $-.465^{* *}$ & $.766^{* *}$ & - & & \\
\hline 5. Agreeableness & .036 & -.024 & .047 & $.141^{*}$ & - & \\
\hline 6. Conscientiousness & $.680^{* *}$ & $.578^{* *}$ & $-.726^{* *}$ & $-.664^{* *}$ & .090 & - \\
\hline
\end{tabular}

As stated in Table 2, when the Pearson correlation coefficients showing the two-way relationship between the variables included in the research are investigated, there appears not to be a significant correlation between agreeableness and performance anxiety levels $(r=.036, \mathrm{p}>.05)$. When the other personality traits and performance anxiety levels are investigated, a positive and high level correlation was identified between emotional balance/neuroticism and performance anxiety levels $(\mathrm{r}=.808, \mathrm{p}<.01)$. There was a moderate negative correlation identified between extraversion and openness to experience with performance anxiety levels ( $\mathrm{r}=-.631$ and $\mathrm{r}=-.563, \mathrm{p}<.01)$. A moderate positive correlation was identified between conscientiousness and performance anxiety level $(\mathrm{r}=.680, \mathrm{p}<.01)$. According to the obtained findings, there was no significant relationship for performance anxiety levels of students and the five factor personality trait of agreeableness only, while there was a significant correlation with the other four personality traits.

The results of standard multiple regression analysis performed to determine the predictive power of the five factor personality traits of music education branch students for individual instrument test performance anxiety are shown in Table 3.

Table 3. Multiple Regression analysis results relating personality traits with performance anxiety

\begin{tabular}{|c|c|c|c|c|c|}
\hline Variables & $\mathrm{B}$ & $\mathrm{Sh}$ & $\beta$ & $\mathrm{t}$ & $\mathrm{p}$ \\
\hline \multicolumn{6}{|l|}{ Performance Anxiety level } \\
\hline Emotional Balance/Neuroticism & .985 & .067 & .600 & 14.803 & .000 \\
\hline Extraversion & -.137 & .054 & -.144 & -2.522 & .012 \\
\hline Openness to experience & -.058 & .055 & -.056 & -1.052 & .294 \\
\hline Agreeableness & .042 & .030 & .048 & 1.417 & .158 \\
\hline Conscientiousness & .246 & .070 & .187 & 3.525 & .001 \\
\hline $\mathrm{R}=.858$ & & & & & \\
\hline$F_{(5-250)}=139.457$ & & & & & \\
\hline
\end{tabular}

When Table 3 is investigated, the five factor personality traits appear to explain $74 \%$ of the total variance in performance anxiety levels $\left(\mathrm{R}=.858, \mathrm{R}^{2}=.736, \mathrm{~F}_{(5-250)}=139.457, \mathrm{p}<.01\right)$. According to t-test results related to significance of regression coefficients, emotional balance/neuroticism $(t=14.803, p<.01)$ and conscientiousness $(t=3.525$, $\mathrm{p}<.01)$ positively and significantly predicted performance anxiety level. Additionally extraversion $(\mathrm{t}=-2.522, \mathrm{p}<.05)$ appears to negatively and significantly predict performance anxiety levels. However, openness to experience ( $\mathrm{t}=-1.052$, $\mathrm{p}>.05)$ and agreeableness $(\mathrm{t}=1.417, \mathrm{p}>.05)$ did not appear to significantly predict performance anxiety levels. According to standardized regression coefficients, the significant predictors of performance anxiety levels are, in order of importance: emotional balance/neuroticism $(\beta=.600)$, conscientiousness $(\beta=.187)$ and extraversion $(\beta=-.144)$. 


\section{Conclusion}

According to the obtained results, we can say there is a significant relationship between the individual instrument performance anxiety levels and five factor personality traits of undergraduate students attending Music Education branches at Fine Arts Education Departments in Education Faculties in Turkey. There was a positive and high level relationship between performance anxiety level and the five factor personality trait of emotional balance/neuroticism, while there was no correlation encountered between agreeableness and performance anxiety levels only. There was a negative correlation between extraversion and openness to experience with performance anxiety, while there was a positive correlation between conscientiousness and performance anxiety.

The results of multiple regression analysis based on these relationships found that the five factor personality traits of emotional balance/neuroticism and conscientiousness positively and significantly predicted performance anxiety level. Extraversion negatively and significantly predicted performance anxiety level, while openness to experience and agreeableness were identified not to significantly predict performance anxiety level.

When correlation and regression results are compared, the levels of the five factor personality traits of emotional balance/neuroticism and conscientiousness changed in direct proportion with individual instrument performance anxiety level, while extraversion changed in inverse proportion to individual instrument performance anxiety level. Though there was a negative correlation found between openness to experience and individual instrument performance anxiety level, this item did not have significant predictive power identified. As students with low levels of openness to experience have high individual instrument performance anxiety, they continuously avoid performance. The absence of significant prediction of individual instrument performance anxiety level by openness to experience is thought to be due to the students answering questions about kinetic concepts like performance based on cognition rather than real experience.

When the relevant literature is investigated, findings support the results of the research. Steptoe and Fidler (1987) in a study of orchestra musicians identified that performance anxiety levels increased linked mostly to neuroticism and daily fears. A study of musicians by Osborne and Franklin (2002) concluded that as the social anxiety levels of musicians increased, performance anxiety increased. Kenny et al. (2004) in a study of choir and opera singers compared performance anxiety with occupational and personality traits and identified a direct relationship between the tendency to anxiety of musicians and performance anxiety. A study by Stephenson and Quarrier (2005) determined that students with higher anxiety sensitivity had higher performance anxiety levels. Kokotsaki and Davidson (2003) in a study of vocal students stated there was a direct proportional relationship between personality traits and performance anxiety. A study of music department students by Yöndem (2012) related the personality traits of students with perceived sufficiency and thought content like negative qualities related to personality traits, negative thinking, fear of being liked and perfectionism with anxiety. Çırakoğlu (2013) identified a positive correlation between musical performance anxiety with perfectionism and trait anxiety in a review study. Tokinan (2014) in a study of music teacher candidates stated there was a significant and negative correlation between music performance anxiety and self-confidence.

In light of these results, the following recommendations are made.

- Research into the personality traits of undergraduate students attending Music Education branches in Fine Arts Education Departments in Education Faculties in Turkey and reduction of anxiety levels to a minimum by direction of individual instrument performance according to these traits is important for greater success in individual instrument performance.

- As there is a significant increase in individual instrument performance levels as emotional balance/neuroticism levels increase, students with this personality trait should be given continuous counseling and guidance services and observation of neurotic behavior will cause a reduction in the individual instrument performance anxiety levels of students.

\section{References}

Bacanl, H., İlhan, T., \& Aslan, S. (2009). Development Of A Personality Scale Based On Five Factor Theory: Adjective Based Personality Test (Abpt). Journal of Turkish Educational Sciences, 7(2), 261-279.

Çırakoğlu, O. C. (2013). The Enemy on the Stage: A Review of Performance Anxiety in Musicians. Turkish Psychological Articles, 16(32), 95-104.

Çivitci, N., \& Arıcıoğlu, A. (2012). Helping Styles and Personality Traits Based on The Five-Factor Theory of Counselor Candidates. Mehmet Akif Ersoy University Journal of Education Faculty, 12(23), 78 - 96.

Costa, P. T., \& McCrae, R. R. (1992). Four Ways Five Factors Are Basics. Personality and Individual Differences, 13(6), 653-665. https://doi.org/10.1016/0191-8869(92)90236-I 
Dalkıran, E., Baltacı, Ş. H., Karataş, \& Nacakcı Z. (2014). Developing of Individual Instrument Performance Anxiety Scale: Validity- Reliability Study. International Journal of Assessment Tools in Education, 1(1), 13-25.

Doğan, T. (2013). The Five Factor Personality Traits and Subjective Well-Being. Journal of Doğuş University, 14(1), 56-64.

Eryılmaz, A., \& Öğülmüş, S. (2010). Subjective Well-Being and Big Five Personality Model at Adolescence. Ahi Evran University Journal of Kırşehir Education Faculty, 11(3), 189-203.

Kenny, D. T., Davis, P., \& Oates, J. (2004). Music Performance Anxiety and Occupational Stress amongst Opera Chorus Artists and Their Relationship with State and Trait Anxiety and Perfectionism. Journal of Anxiety Disorders, 18(6), 757-777. https://doi.org/10.1016/j.janxdis.2003.09.004

Kokotsaki, D., \& Davidson, J. W. (2003). Investigating Musical Performance Anxiety Among Music College Singing Students: A Quantitative Analysis. Music Education Research, 5(1), 45-59. https://doi.org/10.1080/14613800307103

Mount, M. K., Barrick, M. R., Scullen, S. M., \& Rounds, J. (2005). Higher-Order Dimensions of the Big Five Personality Traits and the Big Six Vocational Interest Types. Personnel Psychology, 58, 447-478. https://doi.org/10.1111/j.1744-6570.2005.00468.x

Osborne, M. S., \& Franklin, J. (2002). Cognitive Processes in Music Performance Anxiety. Australian Journal of Psychology, 54(2), 86-93. https://doi.org/10.1080/00049530210001706543

Sığrı, Ü., \& Gürbüz, S. (2010). The Relationship between Personality and Academic Success: A Study on Undergraduates. Journal of Defense Science, 10(1), 30-48.

Somer, O. (1998). Five Factor Personality Inventory. Turkish Psychological Articles, 1(2), 35-62.

Somer, O., Korkmaz, M., \& Tatar, A. (2002). Development of Five Factor Personality Inventory. Turkish Journal of Psychology, 17(49), 21-33.

Stephenson, H., \& Quarrier, N. F. (2005). Anxiety Sensitivity and Performance Anxiety in College Music Students. Medical Problems of Performing Artists, 20(3), 119-126.

Steptoe, A., \& Fidler, H. (1987). Stage Fright in Orchestral Musicians: A Study of Cognitive and Behavioral Strategies in Performance Anxiety. The British Journal of Psychology, 78(2), 241-249. https://doi.org/10.1111/j.2044-8295.1987.tb02243.x

Tokinan, B. Ö. (2014). An Analysis of Prospective Teachers Music Performance Anxiety in Terms of Their Characteristics. Fine Arts, 9(2), 84-100. https://doi.org/10.12739/NWSA.2014.9.2.D0150

Yöndem, Z. D. (2012). Physical, Behavioral and Cognitive Characteristics of Perceived Performance Anxiety in Music Students: A Qualitative Study. Education and Science, 37(166), 181-194.

Zeidner, M. (1998). Test-Anxiety: The State of The Art. New York: Plenum Publishing Corporation. http://books.google.com/books?id=oYBb7iLNiTkC\&printsec=frontcover\&hl=tr\&source=gbs_ge_summary_r\&cad $=0 \# \mathrm{v}=$ onepage $\& \mathrm{q} \& \mathrm{f}=$ false. Erişim tarihi. 30.05.2017

\section{Copyrights}

Copyright for this article is retained by the author(s), with first publication rights granted to the journal.

This is an open-access article distributed under the terms and conditions of the Creative Commons Attribution license which permits unrestricted use, distribution, and reproduction in any medium, provided the original work is properly cited. 